УДК 331.108.4

\title{
РАЗВИТИЕ СПЕЦИАЛИСТА КАК ФАКТОР УСТОЙЧИВОГО РОСТА СОВРЕМЕННОЙ ОРГАНИЗАЦИИ
}

\section{В. В. Борботько ${ }^{1}$}

${ }^{1}$ К.э.н., доцент, доцент кафредры менеджмента учреждения образования «Белорусский государственньй университет информатики и радиоэлектроники», Минск, Беларусь, е-mail: master_1@inbox.ru

\section{Реферат}

Развитие специалиста играет ключевую роль в современной организации. Своевременность определения основных приоритетов развития навыков специалистов влияет на успех всей организации и ее устойчивое развитие.

В данной статье предлагается описание подхода к определению уровня развития специалистов с учетом особенностей управления карьерным ростом.

Ключевые слова: карьера специалиста, рынок труда, организация, работодатель.

\section{DEVELOPMENT OF A SPECIALIST AS A FACTOR OF SUSTAINABLE GROWTH OF A MODERN ORGANIZATION}

\section{Abstract}

\section{V. Borbotko}

The development of the specialist plays a key role in the modern organization. Timeliness of determining the main priorities for the development of skills of specialists affects the success of the entire organization and its sustainable development.

This article proposes a description of the approach to determining the level of development of specialists, taking into account the peculiarities of career management.

Key words: career of a specialist, labor market, organization, employer.

\section{Введение}

В центре рыночной трансформации отечественной экономики находится процесс формирования и становления современного рынка труда. Усилиями ученых и практиков по существу создана научная база исследования этого процесса, ее категориальный аппарат. Вместе с тем незавершенность формирования рынка труда, высокая специфичность данного процесса, его жизненная необходимость для настоящего и будущего страны предопределяют широкую дискуссию по целому ряду узловых проблем. Это в полной мере относится и к теоретическому осмыслению рынка труда, его сущности и содержанию.

Сущность процесса развития специалиста современной организации

Обобщение взглядов исследователей показывает, что большое внимание уделяется всестороннему анализу формирующегося рынка труда, заложены основы его современной отечественной теории. Вместе с тем в отечественных работах реализуются различные подходы к пониманию содержания рынка труда.

В первом случае, рынок труда раскрывается как динамичная система, в которой взаимодействуют, с одной стороны, работодатели (собственники средств производства, предприниматели), а с другой работополучатели (наемные работники), формируя объем, структуру и соотношение спроса и предложения на рабочую силу.

Во втором случае авторы рассматривают рынок труда как механизм согласования интересов работодателей (предъявителей спроса на труд) и наемной рабочей силы (продавцов последней).

Не вступая в дискуссию по поводу предпочтительности того или иного подхода относительно понятия «рынок труда», нам важно выделить содержащиеся в них отдельные положения, имеющие принципиальное значение для понимания сущности и содержания рынка труда как фрактор развития специалиста.

Приоритетными направлениями политики занятости экономически активного населения являются: социальные гарантии труда; социальная защита и поддержка работающих и социальная помощь безработным.
Их реализация возможна, помимо прочего, при соответствующей роли государства. Совокупность указанных элементов формируют систему управления рынком труда, регулируемую государством.

Для осуществления этой основополагающей функции государства необходимо формирование соответствующей правовой базы, финансовой и других форм поддержки и неукоснительное выполнение системы государственных гарантий, включающих [1]:

- гарантии на рынке труда по содействию трудоустройству;

- гарантии смены (по инициативе работника) профессии, включающей обучение, переобучение, повышение квалификации;

- гарантии сохранения профессии (при перемене места работы или отрасли приложения труда);

- гарантии рабочего места (для социально уязвимых слоев), т. е. квотирование рабочих мест;

- гарантии доходов, включая пособие по безработице, доплату при недозанятости по вине работодателя, различные виды помощи безработным и т. д.

В интересах настоящего и будущего страны представляется целесообразным законодательно разработать гарантии повышения уровня общего и профессионального образования, трудоустройства вузовской молодежи, впервые выходящей на рынок труда в возрасте до 24 лет.

Важным моментом становления государственной политики занятости является разработка требований, предъявляемых для занятия различных должностей специалистами, рассмотрим пример.

Современная система образования предполагает совместную работу различных должностей с предъявлением различных требований. Все это создает условия для дифференцирования труда и карьерного роста специалиста. При этом предполагается, что специалист может перейти на следующий уровень в иерархии только в том случае, если он обладает необходимыми квалификационными характеристиками. Однако на практике ситуация чаще всего состоит иначе, и специалист может и не соответствовать предъявляемым требованиям. В результате чего создается десицит знаний, и специалист не в состоянии выполнять необходимые задачи, что приводит к снижению эффрективности труда и решаемых задач. 
Рассмотрим фрагмент модели развития специалиста в рамках описанных уровнях.

Модель развития специалиста может быть рассмотрена во времени с точки зрения карьерного роста. Специалист в процессе своей деятельности приобретает знания, достаточность которых способствует выполнению более сложных задач, и может стать стимулом к процессу продвижения по службе. Лаг времени примерно необходимый для «накопления» знаний составляет около пяти лет для различных рангов должностей.

Все это формирует особенную систему управления развитием специалиста, которая условно может быть разделена на несколько элементов [2]:

1. Подготовительный уровень - получение будущими специалистами первичных знаний и навыков, которым обучают в средних школах. На данном уровне происходит формирование первичных представления о профессиях и собственных интересах людей, закладываются базовые знания, которые в бедующем позволят освоить профильные специальности.

2. Уровень обучения - формирование профрессиональных знаний по выбранной специальности. Реализуется при обучении лиц в высших и средних специальных учебных заведениях. На данном уровне происходит формирование специальных навыков будущего специалиста.

3. Адаптационный уровень - развитие профессиональных навыков молодых специалистов. Реализуется в первые годы работы на предприятиях в должностях, соответствующих полученной специальности. На данном уровне происходит развитие специальных навыков молодого специалиста.

4. Уровень карьерного роста - приобретение специалистом дополнительных навыков, расширение объема знаний специалиста и его вертикальное и горизонтальное перемещение.

При применении описанного подхода в системе управления развития специалиста важно понимать, что для эффективного развития необходимо четкое соотношение между потребным и имеющимся качеством уровня знаний специалиста. Визуально мы видим, что все эти уровни специалист проходит в процессе своей профессиональной деятельности, однако уровень знаний у них разный, а если учесть, что на каждом уровне выделяются минимальные требования, то специалист физически переходит на более высоких уровень, хотя его знания соответствуют более низкому уровню, а следовательно его эфффективность будет невысокой.

На основании представленного фрагмента модели развития специалиста можно сделать вывод о том, что в качестве агрегированных показателей, характеризующих эфффективность реализации каждого из четырех уровней, можно выделить [3]:

1. Группу показателей основной деятельности, которая описывает результативность основных действий, например эффективность обучения в школе, в вузе, эффрективность работы специалиста, эффективность карьерного роста.

2. Группа показателей вспомогательных действий, которая описывает результативность дополнительных действий, реализуемых на каждом уровне развития специалиста, необходимых для качественного перехода на следующий уровень.

Опишем процесс функционирования представленной системь управления развитием специалиста.

На подготовительном уровне в процессе обучения в кружках по интересам происходит формирование первичных представлений о знании и интересах людей, которые впоследствии находят развитие в процессе обучения в средних школах. В качестве показателей основной деятельности тут выступают: эффективность обучения в кружках по интересам (этап 1) и эффрективность обучения в средней школе. В качестве вспомогательного показателя - эффективность обучения в кружках по интересам (этап 2). В случае недостаточности совокупной эфффективности по подготовительному уровню необходима корректировка обучения в кружках по интересам (этап 1).

На уровне обучения происходит формирование основных знаний, умений и навыков будущих молодых специалистов. Поскольку, например, система высшего образования предполагает активное участие не только педагога, но и самого обучаемого, то одним из ключевых факторов в развитии специалиста является процесс дополнительного обучения (самообучение). В качестве основного показателя выступает результативность образовательного процесса, а в качестве дополнительного результативность самообучения. В случае если основной показатель будет иметь низкое значение, то необходима корректировка как самого процесса обучения в ВУЗе, так и процесса обучения в средней школе. Если из описанной схемы убрать самообучение, то уровень образования может иметь положительный результат молодой специалист выходит на рынок труда, однако результативность уровня будет незначительной.

На адаптационной уровне происходит развитие приобретенных навыков молодым специалистом и в качестве оценки эффрективности уровня используются: основной показатель - результативность адаптации молодого специалиста к условиям труда; вспомогательный показатель - результативность самообучения молодого специалиста. Зависимость и между элементами адаптационного уровня аналогична зависимости между элементами уровня обучения.

На уровне карьерного роста происходит вертикальное перемещение в иерархической структуре организации специалиста. В качестве основного показателя можно выделить компетентность специалиста, а в качестве дополнительного - эффеективность самообразования. Зависимость и между элементами уровня карьерного роста аналогична зависимости между элементами предшествующих двух уровней.

Развитие специалиста представляет собой распределение объема знаний по уровням планирования с учетом специфики карьерного роста специалиста. Управление представлено в виде пяти элементов: оперативное, текущее, стратегическое плановое, стратегическое вероятное и стратегическое стохастическое. Такой подход определяется исходя из перечня возможных должностных обязанностей. Специалисты осуществляют работу с транзакционными данными и принимают решения по способу их обработки, формируя оперативный уровень обработки данных. Руководители подразделений обобщают полученные данные с оперативного уровня, агрегируя их до тактических целей. Заместители директоров осуществляют стратегическое планирование на основании результатов работы подразделений и доводимых задач. Директора планируют деятельность на перспективный период с учетом вероятности достижения поставленных целей и оперируют стохастическими данными.

Объем знаний играет ключевую роль в процессе принятия решения. Данный показатель формируется на протяжении периода времени и не всегда соответствует требованиям. Возможны три условных варианта [4]:

1. Объем знаний специалиста и темп их роста незначительны, что не позволяет эффективно принимать решения и приводит к банкротству организации.

2. Объем знаний специалиста и темп их роста средние и не соответствует требованиям. Данная ситуация аналогична предыдущей и эффективность функционирования организации будет незначительной.

3. Объем знаний специалиста и темп их роста соответствуют требованиям. Организация, в которой работает такой специалист, способна к выполнению генерируемых задач.

Из представленного перечня следует, что самым оптимальным вариантом, при котором организация эффективно решает задачи, является третий вариант, однако такая ситуация встречает не всегда.

Ключевая роль вспомогательных показателей в развитии специалиста заключается в описании разницы между результатами основного процесса, в рамках того или иного уровня системы управления, и требуемыми значениями. Именно эта разница и характеризует эфффективность и зависимость от самообучения.

Если сравнивать предложенную модель развития молодого специалиста с другими теориями, например с теорией потребностей А. Мослоу, то можно сказать следующее: для перехода с одного уровня на другой в процессе развития специалиста необходимо постоянное соответствие как основных, так и вспомогательных показателей. В случае, если происходит «просадка» по какому-либо показателю из предшествующих уровней, то реальное состояние развития специалиста ниже и соответствует более низкому уровню.

Если рассматривать систему подготовки кадров, то планирование процесса обучения специалистов должно включать следующие элементы: 
1. Стратегия обучения и развития детей школьного и дошкольного возраста.

2. Стратегия обучения и развития студенческой молодежи.

3. Стратегия обучения и развития персонала организации. Первые две стратегии будут описаны подробно в последующих главах, поэтому опишем третью стратегию.

Развитие персонала в организации - это не разовая акция, а постоянное «прокачивание» деловых и личностных качеств сотрудников. В рамках этой работы руководство организации должно выполнять определённый комплекс действий:

1. Выработка стратегии развития персонала - на стадии разработки стратегии руководитель должен определить, каких результатов Он хочет добиться от сотрудников, какие профеессиональные и личные качества нужно развивать. Стратегия развития персонала может быть ситуативной и системной. В первом случае она привязана к конкретной бизнес-задаче. Такая стратегия реализуется обычно путем внешнего обучения. При системном варианте происходит постоянное обучение и развитие внутри компании. Благодаря этой стратегии сотрудники совершенствуют весь спектр навыков и применяют их на практике без отрыва от производства.

2. Планирование потребности в персонале - чтобы рассчитать, сколько сотрудников нужно компании, специалистам отдела кадров необходимо анализировать значительное количество данных планы предприятия, расходы на обучение персонала и заработную плату, уровень текучести кадров, состояние дел во всех подразделениях и др. Определение потребности в количестве и качестве персонала - сложная математическая задача, которую решают разными способами, в частности, используют метод экспертных оценок, методы компьютерного моделирования.

3. Профессиональное обучение - специалисты, способные двигать компанию вперед, не приходят «из ниоткуда»: их нужно создавать. Выявлять перспективные кадры, подбирать подходящие методы обучения, вкладывать средства в программы развития персонала задачи руководства и отдела персонала. Однако вклад в обучение приносит плоды только тогда, когда процесс построен корректно и поэтапно. Можно заплатить именитому бизнес-тренеру за знания, которые никогда не будут применены на практике - а все потому, например, что тренинг не соответствовал актуальным задачам компании и потребностям сотрудников.

4. Планирование деловой карьеры - важная часть системы развития персонала. Это выгодно не только работнику, но и всей компании. Если сотрудник видит свои перспективы, имеет четкий план карьерного продвижения, растет его лояльность к организации, удовлетворенность работой, а значит, эффективность труда.

Отдельным элементом в планировании карьеры является ротация кадров, которая помогает:

- создавать кадровый резерв (специалист, умеющий выполнять разные функции, при необходимости сможет заменить коллегу);

- быстро адаптировать сотрудников;

- нивелировать конффликтные ситуации и т. д.

5. Работа с кадровым резервом. Кадровый резерв - это сотрудники которые при возникновении срочной потребности смогут занять новые должности без предварительного обучения. Например при увольнении руководителя отдела ему на смену быстро придет подготовленный специалист. Создание кадрового резерва помогает экономить время и средства на обучение персонала, способствует повышению профрессионального уровня работников.

6. Организация адаптации. Когда в компанию принимают новичка, специалист по кадрам должен ввести его в курс дела и помочь адаптироваться к корпоративной обстановке. Чем быстрее и комфортнее протекает этот процесс, тем выше профессиональная отдача, меньше процент текучести кадров, ниже затраты на подбор и подготовку новых кадров.

7. Формирование корпоративной культуры. Корпоративная культура влияет на имидж компании, отношение персонала к работе, определяет психологический климат в организации. Ее формирование включает в себя:

- разработку правил поведения для сотрудников;
- прописывание миссии и ценностей;

- создание бренда;

- мероприятия по сплочению коллектива (тимбилдинг) и т. д.

Для повышения эффективности стратегии развития и обучения персонала организации можно использовать подход, основанный на разработке индивидуальных планов развития персонала. Индивидуальный план развития - это стратегия повышения знаний специалиста, перечень рекомендаций, чтобы обеспечить непрерывное профрессиональное развитие сотрудника с учетом его потребностей и нужд организации. В плане развития предусмотрено ознакомление с профессиональной литературой, прохождение обучающих курсов и тренингов, посещение семинаров, получение дополнительного образования. За прохождение каждого этапа развития устанавливается мотивация. В зависимости от потребностей специалиста она может быть материальной и нематериальной.

\section{Заключение}

Таким образом, представленная модель развития специалиста представляет собой систему управления компетентностью работника, реализуемую во времени, условно, в которой можно выделить три пограничных состояния: десицит знаний, достаточность знаний, избыток знаний. Каждое из состояний характеризует качественный характер профрессионального уровня развития специалиста. Специалист в процессе своего развития проходит через четыре уровня: подготовительный уровень, уровень обучения, адаптационный уровень и уровень карьерного роста. Для оценки результативности функционирования системы управления могут применяться различные показатели, которые условно можно разделить на две группы: показатели характеризующие основные процессы уровней развития и вспомогательные показатели.

Следует понимать, что система управления развитием персонала неотъемлемо связана с таким понятием как качество, а некоторые уровни описанной модели с понятием стандартизации. Исходя из это необходимо определиться с подходами, которые следует применять при работе с категориями, задействованными в процессе развития персонала.

\section{Список цитированных источников}

1. Борботько, В. В. Управление человеческими ресурсами и его роль в современных условиях развития экономики страны / В. В. Борботько // Вестник Брестского государственного технологического университета. - 2019. - № 3. - С. 10-12.

2. Высоцкий, О. А. Теория измерения управляемости хозяйственной деятельности предприятия / Под науч. ред. Р. С. Седегова. - Минск : Право и экономика, 2004. - 396 с.

3. Высоцкий, О. А. Основы устойчивого развития производственной организации / О. А. Высоцкий, И. М. Гарчук, Н.С.Данилова; под науч. ред. В. Ф. Медведева; Брестский государственный технический университет. - Минск : Право и экономика, 2015. - 358 с.

4. Высоцкий, О. А. Диагностика и мониторинг процессов управления хозяйственными системами / О. А. Высоцкий [и др.]; под общей ред. О. А. Высоцкого. - Минск : ЦНИИТУ, 1999. - 234 с.: ил.

\section{References}

1. Borbot'ko, V. V. Upravlenie chelovecheskimi resursami i ego rol' v sovremennyh usloviyah razvitiya ekonomiki strany / V. V. Borbot'ko // Vestnik Brestckogo gosudarstvennogo tekhnologicheskogo universiteta. - 2019. - № 3. - S. 10-12.

2. Vysockij, O. A. Teoriya izmereniya upravlyaemosti hozyajstvennoj deyatel'nosti predpriyatiya / Pod nauch. red. R. S. Sedegova - Minsk : Pravo i ekonomika, 2004. - $396 \mathrm{~s}$.

3. Vysockij, O. A. Osnovy ustojchivogo razvitiya proizvod-stvennoj organizacii / O. A. Vysockij, I. M. Garchuk, N. S. Danilova; pod nauch. red. V. F. Medvedeva; Brestskij gosudarstvennyj tekhnicheskij universitet. - Minsk : Pravo i ekonomika, 2015. - $358 \mathrm{~s}$.

4. Vysockij, O. A. Diagnostika i monitoring processov upravleniya hozyajstvennymi sistemami / O. A. Vysockij [i dr.]; pod obshchej red. O. A. Vysockogo. - Minsk : CNIITU, 1999. - 234 s.: il.

Материал поступил в редакцию 23.01.2021 